\title{
Cytotoxic Effects of Smp24 and Smp43 Scorpion Venom Antimicrobial Peptides on Tumour and Non-tumour Cell Lines
}

\author{
Ranwa A. Elrayess ${ }^{1,2} \cdot$ Mahmoud E. Mohallal $^{2} \cdot$ Yomn M. El-Shahat ${ }^{2,3} \cdot$ Hala M. Ebaid $^{2} \cdot$ Keith Miller $^{1} \cdot$ Peter N. Strong ${ }^{1}$. \\ Mohamed A. Abdel-Rahman ${ }^{2}$
}

Accepted: 12 September 2019 / Published online: 12 October 2019

(c) The Author(s) 2019

\begin{abstract}
Smp24 and Smp43 are novel cationic AMPs identified from the venom of the Egyptian scorpion Scorpio maurus palmatus, having potent activity against both Gram-positive and Gram-negative bacteria as well as fungi. Here we describe cytotoxicity of these peptides towards three non-tumour cell lines (CD34 ${ }^{+}$(hematopoietic stem progenitor from cord blood), HRECs (human renal epithelial cells) and HACAT (human skin keratinocytes) and two acute leukaemia cell lines (myeloid (KG1a) and lymphoid (CCRF-CEM) leukaemia cell lines) using a combination of biochemical and imaging techniques. Smp24 and Smp43 (4-256 $\mu \mathrm{g} / \mathrm{mL})$ decreased the cell viability (as measured by intracellular ATP) of all cells tested, although keratinocytes were markedly less sensitive. Cell membrane leakage as evidenced by the release of lactate dehydrogenase was evident throughout and was confirmed by scanning electron microscope studies.
\end{abstract}

Keywords Scorpio maurus palmatus $\cdot$ Antimicrobial peptide $\cdot$ Smp24 $\cdot$ Smp43 $\cdot$ Cell death

\section{Introduction}

Over the last decades, an increasing number of pathogenic microorganisms have developed resistance to conventional antibiotics posing problems in the management of infection. The rapid increase in drug-resistant infections emphasizes the urgent need to develop novel reagents with new modes of action (see, inter alia Bahar and Ren 2013). The development of agents with a low potential to resistance is technically challenging and is a contributing factor in the declining discovery of novel classes of antibiotics.

Antimicrobial peptides (AMPs) are essential to the innate immune system across all phyla and have the potential as a novel therapeutic class of broad-spectrum antibiotics due to

Peter N. Strong

p.strong@shu.ac.uk

Mohamed A. Abdel-Rahman

mohamed_hassanain@science.suez.edu.eg

1 Biomolecular Sciences Research Centre, Sheffield Hallam University, Sheffield S1 1WB, UK

2 Zoology Department, Faculty of Science, Suez Canal University, Ismailia 41522, Egypt

3 Zoology Department, Faculty of Science, Suez University, Suez, Egypt their selectivity for prokaryotic membranes (Bahar and Ren, 2013). AMPs are generally positively charged, amphipathic molecules between 12 and 70 amino acids in length. They target and disrupt prokaryotic membranes due to the initial electrostatic attraction to the negatively charged membrane surface (Huang 2000; Zasloff 2002). A threshold concentration is (often) then required before membrane disruption occurs. A multitude of models and mechanisms have been proposed to account for this subsequent disruption (Teixeira et al. 2012; Heath et al. 2018). One key challenge to developing AMPs as therapeutic agents is to minimize and hopefully eliminate any cytolytic effects on eukaryotes. The lack of overall surface charge on eukaryotic membranes provides hope that this particular goal can be achieved. Although healthy eukaryotic cell membranes are zwitterionic, the transbilayer movement of phosphatidylserine to the outer membrane leaflet in tumour cells (for a review, see Sharma and Kanwar 2018), also provides cancer cells, analogously to prokaryotic cells, with a negatively charged outer membrane. The appearance of phosphatidylserine on the outer membrane leaflet regulates malignant transformation by primarily suppressing anti-tumour immune responses (Utsugi et al. 1991). These observations have led to many suggestions that AMPs might be effective anti-cancer agents (Wang and Wang 2016; Crusca et al. 2018), providing that there is 
a sufficient distinction (effective therapeutic index) between cytolytic effects on tumour and non-tumour cell membranes.

Scorpion venoms are cocktails of diverse biologically active compounds (see, inter alia, Rodriguez de la Vega and Possani, 2005; Rodriguez de la Vega et al. 2010; Cao et al. 2014; Abdel-Rahman et al. 2015; Cid-Uribe et al. 2018; Kazemi and Sabatier, 2019) and provide a rich source of AMPs (for reviews see Harrison et al. 2014; Wang and Wang, 2016; El-Bitar et al. 2019). Abdel-Rahman et al. (2013) identified two novel amphipathic cationic AMPs (Smp43 and Smp24) through cDNA sequencing of the venom gland of the Egyptian scorpion Scorpio maurus palmatus. Both peptides showed a potent activity against both Gram-positive and Gram-negative bacteria as well as fungi (Harrison et al. 2016a) and also formed pores in model prokaryotic and eukaryotic phospholipid membranes. The mechanism of membrane disruption caused by Smp24 depended on phospholipid composition; the peptide formed toroidal pores in prokaryotic-like membranes but hexagonal phase non-lamellar phase structures were seen in eukaryotic-like membranes (Harrison et al. 2016b). In comparison, Smp43 disrupted both types of membranes by a common mechanism that involves elements of both the carpet model and the expanding pore mechanism, that we have termed "diffusion-limited disruption" (Heath et al. 2018). Here in more detail, we have set out to study the cytotoxic effects of Smp24 and Smp43 on non-tumour (hematopoietic stem cells, primary renal cells and immortalised keratinocytes) and tumour (myeloid and lymphoid leukaemia) eukaryotic cells lines.

\section{Materials and Methods}

\section{Materials}

Cell Titre-Glo® reagent kit was obtained from Promega (Southampton, UK). RPMI media was obtained from Invitrogen (Paisley, Scotland). DMEM media was obtained from Lonza (Cologne, Germany). Epithelial growth media was obtained from Innoprot (Deria, Spain). 96-well white microplates were obtained from Fisher Scientific (Loughborough, UK). All other reagents were the highest grade available and were obtained from Sigma (Gillingham, UK).

\section{Peptides}

The sequence of both Smp24 (IWSFLIKAATKLLPSLFGGGKKDS) and Smp43 (GVWDWIKKTAGKIWNSEPVKALKSQALNAAKNFVAEKIGATPS) (AbdelRahman et al. 2013) were synthesized (> 90\% pure) using solid-phase chemistry and were purchased from Think Peptides ${ }^{\circledR}$ (Oxford, UK).

\section{Cell Lines}

Non-tumour haematopoietic progenitor stem cells $\left(\mathrm{CD} 34^{+}\right)$ were obtained from Stem Cell Technologies (Grenoble, France). Primary Human renal epithelial cells (HRECS) were obtained from Innoprot (Spain). Immortalized human skin keratinocytes $(\mathrm{HaCaT})$ was obtained from Thermofisher Scientific (UK). Human lymphoid leukaemia cells (CCRFCEM, acute lymphoblastic leukaemia, ATCC: CCL-119) and human myeloid leukaemia cells (KG-1a, acute mylogenous leukaemia, ATCC: CCL-243) were obtained from the ATCC (Teddington, UK). MycoAlert ${ }^{\mathrm{TM}}$ mycoplasma detection kits were obtained from Lonza (Cologne, Germany).

\section{Culture Conditions}

Suspended cells (CD34 ${ }^{+}$, CCRF-CEM and KG-1a) were seeded in $775 \mathrm{~cm}^{2}$ flasks in RMPI 1640 medium supplemented with $10 \%(\mathrm{v} / \mathrm{v})$ foetal bovine serum (FBS), $1.5 \mathrm{mM}$ L-glutamine and $100 \mu \mathrm{g} / \mathrm{mL}$ penicillin/streptomycin. HaCaT cells were seeded in $775 \mathrm{~cm}^{2}$ flasks in DMEM medium supplemented with $10 \%$ FBS, $1.5 \mathrm{mM}$ L-glutamine and $100 \mu \mathrm{g} /$ $\mathrm{mL}$ penicillin/streptomycin. HRECs were seeded in $\mathrm{T} 75 \mathrm{~cm}^{2}$ flasks in epithelial cell media containing $2 \%$ FBS, $1 \%$ epithelial cell growth supplement (EPICGS) and $1 \%$ penicillin/ streptomycin. Cells were incubated at $37{ }^{\circ} \mathrm{C}$ with $5 \% \mathrm{CO}_{2}$ and tested regularly for mycoplasma contamination; all cells were negative throughout the study.

\section{Cell Viability Assay}

Cell viability was determined by measuring intracellular ATP levels, using a Cell Titre-Glo® luminescent cell viability assay (Promega). Cells were seeded into white 96-well plates at $2.5 \times 10^{4}$ cells/well and were treated with either Smp24 and Smp43 or water (vehicle control) and 10\% Triton X-100 (positive control). Cells were incubated $\left(37^{\circ} \mathrm{C}\right)$ for $24 \mathrm{~h}$, followed by addition of Cell Titer-Glo ${ }^{\circledR}$ reagent $(100 \mu \mathrm{L})$, according to the manufacturer's instructions. Luminescence (proportional to the amount of ATP present in the cells) was measured using a Victor 1420 luminescence detector (Perkin Elmer, Cambridge, UK). Mean values from three independent experiments were calculated and all treated samples were normalised to controls. The $\mathrm{LC}_{50}$ was determined for each peptide in each cell line. $\mathrm{LC}_{50}$ was calculated from a linear regression equation of each standard curve for each peptide with each cell line. The percentage of ATP level normalized to vehicle controls. 


\section{Lactate Dehydrogenase Assay}

Lactic dehydrogenase (LDH) was measured using a Pierce LDH Cytotoxicity Assay Kit (Thermo Scientific, UK). Cells were seeded in 96 well plates at $2.5 \times 10^{4}$ cells/well and treated with either Smp 24 and Smp43 or water (negative control) and $10 \%$ Triton X-100 (positive control). Cells were incubated $\left(37^{\circ} \mathrm{C}\right)$ for $24 \mathrm{~h}$. A maximum LDH activity control was included by treating cells with $10 \times$ lysis buffer $(10 \mu \mathrm{L})$, included in the kit. Following treatments, cell supernatants $(50 \mu \mathrm{L})$ were treated with detection reagent $(50 \mu \mathrm{L})$ according to the manufacturer's instructions. LDH activity was measured at $490 \mathrm{~nm}$ and the \% LDH released was determined, relative to the maximum activity control. The experiment was performed in triplicate and mean values from three independent experiments were calculated.

\section{Scanning Electron Microscopy (SEM)}

Suspended cells were seeded in 6 well plates at $0.5 \times 10^{6}$ cells/well while adherent cells were cultured on a cover slip in 6 well plates at $0.5 \times 10^{6}$ cells/well. The cells were then treated for $24 \mathrm{~h}$ with different concentrations of Smp24 or Smp43 and water as vehicle control. The suspended cells were harvested and centrifuged at $5000 \mathrm{rpm}$ at $4{ }^{\circ} \mathrm{C}(5 \mathrm{~min})$ and the supernatant was removed and cell pellets were collected. The cell pellets and cover slips (carrying adherent cells) were washed twice in $200 \mu \mathrm{L}$ cold $0.1 \mathrm{M}$ phosphate buffer solution (PBS). Then these cells were fixed by adding $100 \mu \mathrm{L}$ of $3 \%$ glutaraldehyde in $0.1 \mathrm{M}$ PBS $24 \mathrm{~h}$ at $4{ }^{\circ} \mathrm{C}$. The cells were washed twice with cold 0.1 M PBS each for 15 min at RT but without spinning. Secondary fixation was carried out in $1 \%$ aqueous osmium tetraoxide for one hour at RT. Cells were then washed twice with 0.1 M PBS at $4{ }^{\circ} \mathrm{C}$ followed by ascending series of ethanol for dehydration (75\%, 95\%, and then twice in $100 \%$ each step $15 \mathrm{~min}$ ). After discarding ethanol, equal amount (1:1) of $100 \%$ ethanol and $100 \%$ hexamethyldisilazane were added for $30 \mathrm{~min}$ followed by $100 \%$ hexamethyldisilazane for another $30 \mathrm{~min}$ at RT to ensure complete removal of water from samples. After completion of drying, the samples were mounted on $12.5 \mathrm{~mm}$ diameter stumps and attached with Carbon-Sticky Tabs and then coated in an Edwards S150B sputter gold coater with approximately $25 \mathrm{~nm}$ of gold. Finally, the cells were then examined and photographed by a scanning electronic microscope (Philips XL20, Germany).

\section{Statistical Analysis}

Data were analysed (unpaired student- $t$ test) using Prism 6 software (Graph Pad). Means and standard errors were calculated and results were considered statistically significant at $\mathrm{P} \leq 0.05$ and highly significant at $\mathrm{P} \leq 0.001$.

\section{Results}

Smp24 and Smp43 (at concentrations between 4 and $256 \mu \mathrm{g} / \mathrm{mL}$ ) both significantly reduced cell viability after $24 \mathrm{~h}$ in all cells tested (CD34 ${ }^{+}$, HREC, HaCaT, KG1-a and CCRF-CEM), as evidenced by concentration-dependent reductions in intracellular ATP levels (Fig. 1). Both myeloid (KG1-a) and lymphoid (CCRF-CEM) leukemic tumour cell lines (Fig. 1a and b respectively) were more sensitive to Smp peptides than non-tumour cell lines (Fig. 1c, d and e). The mean $\mathrm{LC}_{50}$ value of the two tumour cell lines (16 and $14.5 \mu \mathrm{g} / \mathrm{mL}$ for Smp24 and Smp43, respectively) was significantly different $(\mathrm{p} \leq 0.05)$ from the mean $\mathrm{LC}_{50}$ value of the three non-tumour cells (36.7 and $70 \mu \mathrm{g} / \mathrm{mL}$ for Smp24 and Smp43, respectively). There was a considerable variation in the sensitivity to non-tumour cells $\left(\mathrm{CD} 34^{+}\right.$stem cells, primary renal cells (HREC) and the transformed keratinocyte cell line, $\mathrm{HaCaT}$ ) and no apparent correlation between the cytotoxic profiles of Smp24 and Smp43 (Table 1).

The cytotoxic effects of Smp24 and Smp43 were also evidenced by the concentration-dependent release of lactate dehydrogenase (LDH) from all cells tested (Fig. 2). In parallel to measurements of intracellular ATP content (Fig. 1), leakage of LDH from the two leukaemia cell lines was more sensitive to Smp43 than either CD $34^{+}$stem cells or primary renal cells. In comparison, the cytotoxic effects of Smp24 were indistinguishable. Interestingly, $\mathrm{HaCaT}$ plasma cell membranes were much more resistant to the cytotoxic effects of both Smp24 and Smp43 (Fig. 2e) and this was also reflected in the ATP assay (Fig. 1e). Scanning electron micrographs of cells treated with either Smp24 or Smp43 showed evidence of loss of cell filipodia and membrane microvilli, as well as pore formation and the appearance of cell membrane blebs (Fig. 3).

\section{Discussion}

Scorpion venoms have provided a rich source of AMPs and the possibilities of developing their therapeutic potential is enhanced when it can be demonstrated that such peptides have limited cytotoxic effects on mammalian cells. For example, the considerably lower cytotoxic effects of Smp24 against stem cells (e.g. CD $34^{+}$) and primary cells (e.g. HRECs) $\left(\mathrm{LC}_{50} 20-37 \mu \mathrm{g} / \mathrm{mL}\right)$ described here is in contrast with the significantly higher antimicrobial activity of Smp24 against strains of Staphylococcus and Bacillus ( $\mathrm{LC}_{50} 4-8 \mu \mathrm{g} / \mathrm{mL}$ ) (Harrison et al. 2016a).

The present investigation of the cytotoxic effects of Smp24 and Smp43 revealed a concentration-dependent 

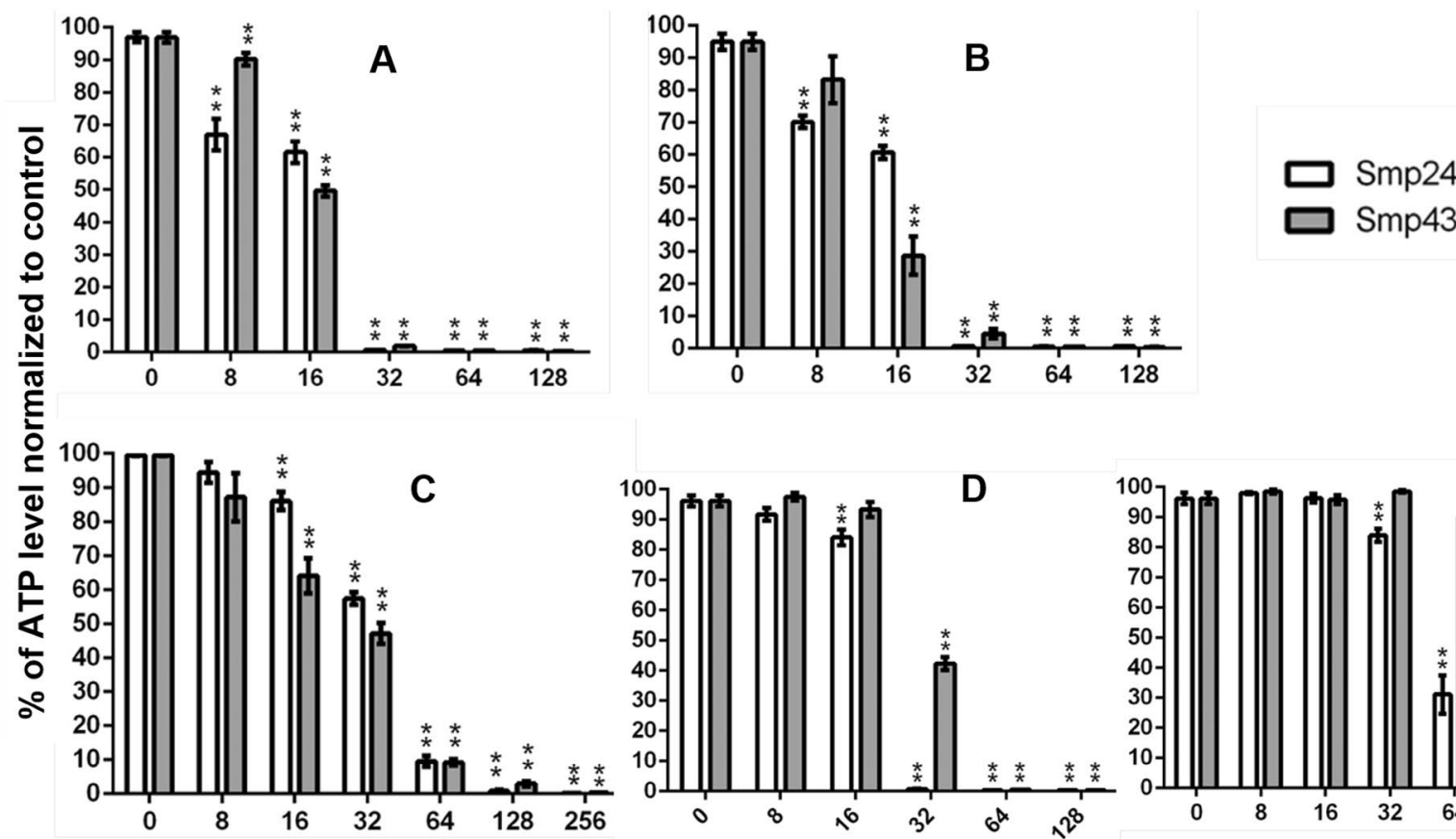

\section{Peptide concentrations $(\mu \mathrm{g} / \mathrm{mL})$}

Fig. 1 Effects of Smp24 and Smp43 on cellular ATP levels of tumour and non-tumour cell lines. Tumour (KG-1a and CCRF-CEM; Panels a and b, respectively) and non-tumour (HREC, CD34 ${ }^{+}$and $\mathrm{HaCaT}$; Panels $\mathbf{c}, \mathbf{d}$ and $\mathbf{e}$, respectively) cell lines were treated with either

Table $1 \mathrm{LC}_{50}$ values (50\%ATP levels, normalized to controls) of cell lines treated with $\mathrm{Smp}$ peptides $(\mu \mathrm{g} / \mathrm{mL})$

\begin{tabular}{lllllll}
\hline Peptides & \multicolumn{2}{l}{ Non-tumour cell lines } & & \multicolumn{2}{l}{ Tumour cell lines } \\
\cline { 2 - 3 } & $\mathrm{CD}^{2} 4^{+}$ & HREC & HaCaT & & KG1-a & CCRF-CEM \\
\hline Smp24 & $20 \pm 0.3$ & $37 \pm 1.2$ & $53 \pm 1.5$ & & $16 \pm 1.3$ & $16 \pm 0.9$ \\
Smp43 & $32 \pm 0.6$ & $28 \pm 0.3$ & $150 \pm 2.9$ & & $16 \pm 0.7$ & $13 \pm 1.5$ \\
\hline
\end{tabular}

Tumour or non-tumour cell lines were treated with either Smp24 or Smp43 for $24 \mathrm{~h}$ at $37^{\circ} \mathrm{C}$. $\mathrm{LC}_{50}$ values presented as mean $\pm \mathrm{SE}$

reduction in cellular ATP levels in both tumour and nontumour cell lines, resulting in the loss of cell viability. Although Smp24 and Smp43 appeared to inhibit the viability of all cells, both lymphoid and myeloid leukaemia cell lines were more sensitive ( $\mathrm{LC}_{50}$ values $13-16 \mu \mathrm{g} / \mathrm{mL}$ ) in comparison to the non -tumour cell lines (stem cells, primary renal cells and keratinocytes), with $\mathrm{LC}_{50}$ values ranging from 20 to $53 \mu \mathrm{g} / \mathrm{mL}$ ). The loss of membrane integrity, suggested by these ATP studies, was confirmed by complementary studies demonstrating leakage of LDH from all the cells tested. Previous studies have shown that scolopendrasin-VII, an AMP identified by de novo RNA sequencing of the centipede Scolopendra subspinipes mutilans (Lee et al 2015), ABP-CM4, a cecropin-like AMP
Smp24 or Smp43 and cellular ATP levels measured with a Cell TitreGlo assay. Treated cells showed a significant $(* * \mathrm{P} \leq 0.001)$ decrease from untreated controls. Data presented as mean $\pm \mathrm{SE}$, using an unpaired student t-test

from the haemolymph of the Chinese silkworm, Bombyx mori (Chen et al. 2010) and polybia-MP from the venom of the Brazilian social wasp, Polybia paulista (Wang et al 2009) all reduced the viability of different leukaemia cell lines in concentration-dependent manner.

Moreover, the SEM studies were conducted to gain more details about morphological disruption induced by Smp24 and Smp43. The results showed that both peptides induced various concentration-dependant morphological alternations on the cell membrane of all cells tested. These alternations were represented by losing cell membrane microvilli and filopodia, pore formation, development of membrane blebs and disintegrated cell membranes. These data confirmed the results obtained from the ATP and LDH assays. Previously, similar results were reported by different AMPs. For instance, Lu et al. (2016) observed that leukemia cell lines treated with the antimicrobial peptide of PFR displayed irregular shape, corrugated surface, cell swelling, bubbles protruding from their membranes and membrane disruption. Moreover, temporin-1CEa AMP incubated with breast cancer cells showed shriveled, invaginated and disrupted cell membranes (Wang et al. 2013). Similarly, hepcidin1-5 AMP induced pore formation and cell swelling in HepG2, HeLa, and HT1080 cell lines (Chang et al. 2011). Pore formation and membrane disruption were also reported in human 


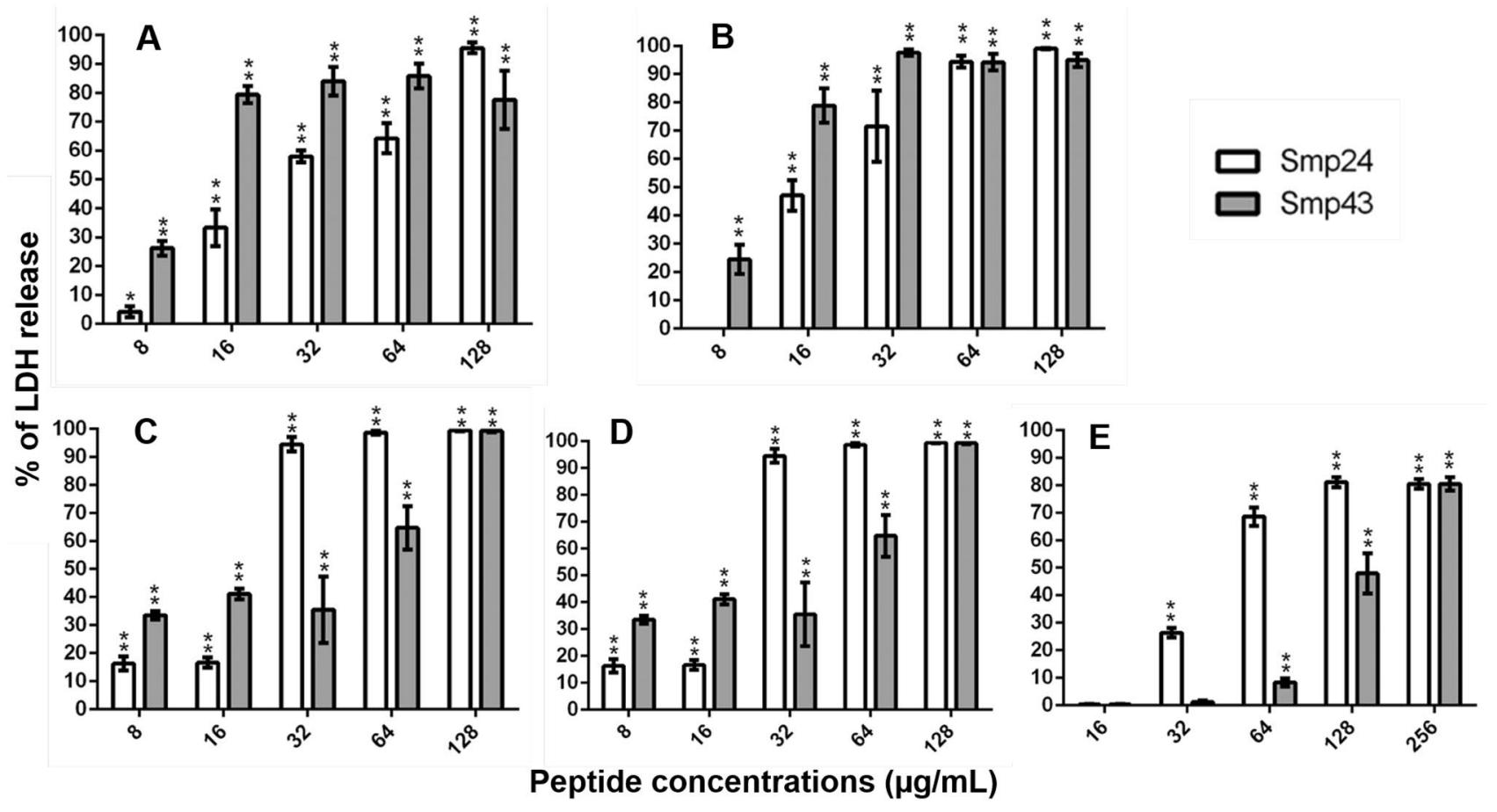

Fig. 2 Effects of Smp24 and Smp43 on cell membrane integrity of tumour and non-tumour cell lines, as evidenced by LDH release. Tumour (KG-1a and CCRF-CEM; Panels A and B, respectively) and non-tumour (HREC, CD34 ${ }^{+}$and HaCaT; Panels C, D and E, respectively) cell lines were treated with either Smp24 or Smp43 and the

bladder cancer cells treated with magainin II and cecropin B AMPs (Lehmann et al. 2006; Suttmann et al. 2008).

It has previously been suggested that AMPs might be effective anti-cancer agents (Wang and Wang 2016; Crusca et al. 2018), due to surface membrane charge differences. The outer plasma membrane leaflet in normal cells exhibits an overall neutral charge as its main components are the zwitterionic phospholipids, phosphatidylcholine and sphingomyelin (Dolis et al. 1997; Hoskin and Ramamoorthy, 2008; Riedl et al. 2014). In contrast, membrane of cancer cells is negatively charged, due to the exposure of the negatively charged phospholipid phosphatidylserine on their outer leaflet (Ran and Thorpe. 2002; Márquez et al. 2004; Schroder-Borm et al. 2005; Dobrzyn'ska et al. 2013). The electrostatic interaction between the positively charged AMPs and the negatively charged components in a cell membrane was believed to play a major role in target selectivity (Lu et al. 2016). Therefore, the unique membrane composition in tumour cells may make them more susceptible release of $\mathrm{LDH}$ was measured. Treated cells showed significant $(* * \mathrm{P} \leq 0.001)$ effects with respect to untreated controls, in a concentration dependent manner. Data presented as mean $\pm \mathrm{SE}$, using an unpaired student t-test

to targeting by cationic AMPs such as the scorpion venom peptides studied here.

It is clear that a range of mammalian cell types need to be assayed when testing Smp peptides for toxicity. In a previous study (Harrison et al 2016a), we have shown that Smp43 has very low haemolytic activity $(1.2 \% \pm 0.5 \%$ lysis at $512 \mu \mathrm{g} / \mathrm{mL}$ ) in comparison with the release of ATP from all the cell lines (tumour and non-tumour) tested here (ca. $100 \%$ at the same concentration). In comparison, Smp24 caused significant erythrocyte disruption $(89.6 \% \pm 5.6 \%)$ at $512 \mu \mathrm{g} / \mathrm{mL}$ and the dose-dependent effect of ATP release from the non-tumour cell lines studied here (Fig. 1) paralleled both the haemolytic activity and the ATP release from HepG2 cells studied previously (Harrison et al 2016a). Although Smp24 and Smp43 have highest potency against gram positive bacteria (MIC values 4-32 $\mu \mathrm{g} / \mathrm{mL}$ ), both myeloid (KG1-a) and lymphoid (CCRF-CEM) leukemic tumour cell lines were more sensitive to Smp peptides than the non-tumour cell lines; however the sensitivity to the tumour cell lines was more akin to that of gram-negative bacteria (Harrison et al 2016a).

Acknowledgements RAE acknowledges a Channel Scholarship to study at Sheffield Hallam University, provided by the Egyptian 

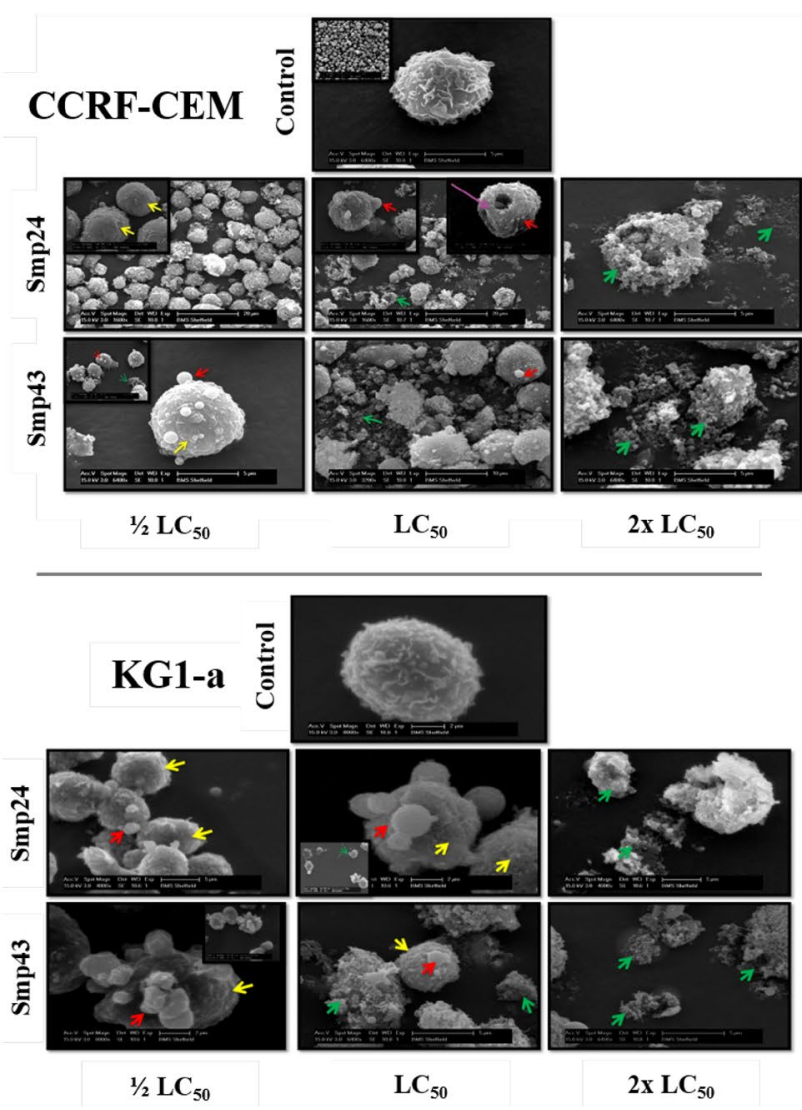

Fig. 3 Scanning electron micrograph of CD34 ${ }^{+}, \mathrm{HaCaT}$, CCRF-CEM and KG1-a cells showing the effects of Smp24 and Smp43 treatment on their cell membrane. Treated cells revealed increases in microvilli loss (yellow arrow), appearance of cell membrane blebs (red

Ministry of Education. KM and PNS acknowledge support from the Biosciences Molecular Research Centre, Sheffield Hallam University.

\section{Compliance with Ethical Standards}

Conflict of interest The authors declare that they have no conflict of interest.

Open Access This article is distributed under the terms of the Creative Commons Attribution 4.0 International License (http://creativeco mmons.org/licenses/by/4.0/), which permits unrestricted use, distribution, and reproduction in any medium, provided you give appropriate credit to the original author(s) and the source, provide a link to the Creative Commons license, and indicate if changes were made.

\section{References}

Abdel-Rahman MA, Quintero-Hernandez V, Possani LD (2013) Venom proteomic and venomous glands transcriptomic analysis of the Egyptian scorpion Scorpio maurus palmatus (Arachnida: Scorpionidae). Toxicon 74:193-207

Abdel-Rahman MA, Harrison PL, Strong PN (2015) Snapshots of scorpion venomics. J Arid Environ 112:170-176
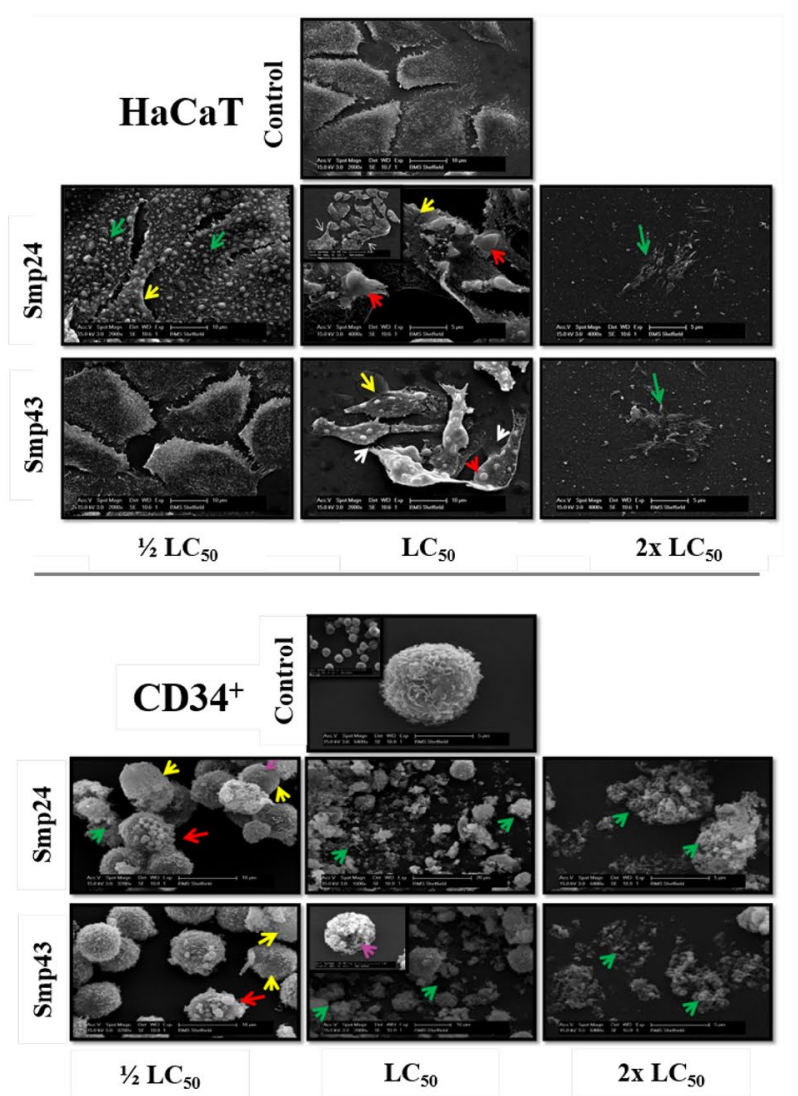

arrow), losing cell membrane filopodia (white arrow), cell membrane pore formation (purple arrow) and disintegrated cell membranes and destroyed cells (green arrow) (Color figure online)

Bahar AA, Ren D (2013) Antimicrobial peptides. Pharmaceutics 6:1543-1575

Cao Z, Di Z, Wu Y, Li W (2014) Overview of scorpion species from China and their toxins. Toxins 6:796-815

Chang WT, Pan CY, Rajanbabu V, Cheng CW, Chen JY (2011) Tilapia (Oreochromis mossambicus) antimicrobial peptide, hepcidin 1-5, shows antitumor activity in cancer cells. Peptides 32:342-352

Chen YQ, Min C, Sang M, Han YY, Ma X, Xue XQ, Zhang SQ (2010) A cationic amphiphilic peptide ABP-CM4 exhibits selective cytotoxicity against leukemia cells. Peptides 31:1504-1510

Cid-Uribe JI, Santibáñez-López CE, Meneses EP, Batista CVF, Jiménez-Vargas JM, Ortiz E, Possani LD (2018) The diversity of venom components of the scorpion species Paravaejovis schwenkmeyeri (Scorpiones: Vaejovidae) revealed by transcriptome and proteome analyses. Toxicon 1(151):47-62

Crusca E Jr, Basso LGM, Altei WF, Marchetto R (2018) Biophysical characterization and antitumor activity of synthetic Pantinin peptides from scorpion's venom. Biochim Biophys Acta Biomembr 860(11):2155-2165

Dobrzyn'ska L, Elzbieta S, Figaszewski Z (2013) Changes in electric properties of human breast cancer cells. J Membr Biol 246:161-166

Dolis D, Moreau C, Zachowski A, Devaux PF (1997) Aminophospholipid translocase and proteins involved in transmembrane phospholipid traffic. Biophys Chem 68(1-3):221-231 
El-Bitar AMH, Sarhan M, Abdel-Rahman MA, Quintero-Hernandez V, Aoki-Utsubo C, Moustafa MA, Possani LD, Hotta H (2019) Smp76, a scorpine-like peptide isolated from the venom of the scorpion Scorpio maurus palmatus, with a potent antiviral activity against hepatitis $\mathrm{C}$ virus and dengue virus. Int $\mathrm{J}$ Pept Res Ther. https://doi.org/10.1007/s10989-019-09888-2

Harrison PL, Abdel-Rahman MA, Miller K, Strong PN (2014) Antimicrobial peptides from scorpion venoms. Toxicon 88:115-137

Harrison PL, Abdel-Rahman MA, Strong PN, Tawfik MM, Miller K (2016a) Characterisation of three alpha-helical antimicrobial peptides from the venom of Scorpio maurus palmatus. Toxicon 117:30-36

Harrison PL, Heath GR, Johnson BRG, Abdel-Rahman AM, Strong PN, Evans SD, Miller K (2016b) Phospholipid dependent mechanism of smp24, an $\alpha$-helical antimicrobial peptide from scorpion venom. Biochim Biophys Acta 1858:2737-2744

Heath GR, Harrison PL, Strong PN, Evans SD, Miller K (2018) Visualization of diffusion limited antimicrobial peptide attack on supported lipid membranes. Soft Matter 14(29):6146-6154

Hoskin DW, Ramamoorthy A (2008) Studies on anticancer activities of antimicrobial peptides. Biochim Biophys Acta Biomembr 1778(2):357-375

Huang HW (2000) Action of antimicrobial peptides: two-state model. Biochemistry 39:8347-8352

Kazemi SM, Sabatier JM (2019) Venoms of Iranian scorpions (Arachnida, scorpiones) and their potential for drug discovery. Molecules $24: 2670$

Lee JH, Kim I, Kim S, Kim M, Yun Y, Nam S, Ahn M, Kang D, Hwang J (2015) Anticancer activity of the antimicrobial peptide Scolopendrasin VII derived from the Centipede, Scolopendra subspinipes mutilans. J Microbiol Biotechnol 25(8):1275-1280

Lehmann J, Retz M, Sidhu SS, Suttmann H, Sell M, Paulsen F, Harder J, Unteregger G, Michael S (2006) Antitumor activity of the antimicrobial peptide magainin II against bladder cancer cell lines. Eur Urol 50:141-147

Lu Y, Zhang T, Shi Y, Zhou H, Chen Q, Wei B, Wang X, Yang T, Chinn E, Kang J, Fu C (2016) PFR peptide, one of the antimicrobial peptides identified from the derivatives of lactoferrin, induces necrosis in leukemia cells. Nat Sci Rep 6:20-23

Márquez M, Nilsson S, Lennartsson L, Liu Z, Tammela T, Raitanen M, Holmberg AR (2004) Charge-dependent targeting: results in six tumor cell lines. Anticancer Res 24(3a):1347-1351

Ran S, Thorpe PE (2002) Phosphatidylserine is a marker of tumor vasculature and a potential target for cancer imaging and therapy. Int J Radiat Oncol 54:1479-1484
Riedl S, Rinner B, Schaider H, Lohner K, Zweytick D (2014) Killing of melanoma cells and their metastases by human lactoferricin derivatives requires interaction with the cancer marker phosphatidylserine. Biometals 27:981-997

de la Vega RCR, Possani LD (2005) Overview of scorpion toxins specific for $\mathrm{Na}^{+}$channels and related peptides: biodiversity, structure-function relationships and evolution. Toxicon 46:831-844

de la Vega RCR, Schwartz EF, Possani LD (2010) Mining on scorpion venom biodiversity. Toxicon 56:1155-1161

Schroder-Borm H, Bakalova R, Andra J (2005) The NK-lysin derived peptide NK-2 preferentially kills cancer cells with increased surface levels of negatively charged phosphatidylserine. FEBS Lett 579:6128-6134

Suttmann H, Retz M, Paulsen F, Harder J, Zwergel U, Kamradt J, Wullich B, Unteregger G, Stöckle M, Lehmann J (2008) Antimicrobial peptides of the cecropin-family show potent antitumor activity against bladder cancer cells. BMC Urol 8:5

Teixeira V, Feio MJ, Bastos M (2012) Role of lipids in the interaction of antimicrobial peptides with membranes. Prog Lipid Res 51(2):149-177

Utsugi T, Schroit AJ, Connor J, Bucana CD, Fidler IJ (1991) Elevated expression of phosphatidylserine in the outer membrane leaflet of human tumor cells and recognition by activated human blood monocytes. Cancer Res 51(11):3062-3066

Wang X, Wang G (2016) Insights into antimicrobial peptides from spiders and scorpions. Protein Pept Lett 23(8):707-721

Wang KR, Yan JX, Zhang BZ, Song JJ, Jia PF, Wang R (2009) Novel mode of action of polybia-MPI, a novel antimicrobial peptide, in multi-drug resistant leukemic cells. Cancer Lett 278:65-72

Wang C, Tian LL, Li S, Li HB, Zhou Y, Wang H, Yang Q, Ma L, Shang D (2013) Rapid cytotoxicity of antimicrobial peptide tempoprin$1 \mathrm{CEa}$ in breast cancer cells through membrane destruction and intracellular calcium mechanism. PLoS ONE 8(4):e60462

Zasloff M (2002) Antimicrobial peptides of multicellular organisms. Nature 415(6870):389-395

Publisher's Note Springer Nature remains neutral with regard to jurisdictional claims in published maps and institutional affiliations. 